\title{
A Simulation Based Study of A Greenhouse SYSTEM WITH INTELLIGENT FUZZY LOGIC
}

\author{
Niaz Mostakim ${ }^{1}$, Shuaib Mahmud ${ }^{2}$ and $*$ Khalid Hossain Jewel ${ }^{3}$ \\ ${ }^{1}$ Department of EEE, Atish Dipankar University of Science and Technology, \\ Uttara, Dhaka. \\ ${ }^{2}$ Department of EEE, Jatiya Kabi Kazi Nazrul Islam University, Trishal, \\ Mymensingh, Bangladesh. \\ ${ }^{3}$ Department of EEE, Islamic University, Kushtia, Bangladesh.
}

\begin{abstract}
Greenhouse (GHS) system is a system, that provides an efficient condition to grow plants. This research paper describes designing of a greenhouse system to control climate, soil moisture, lighting using fuzzy logic. The proposed model consists fuzzy logic to control GHS parameter such as temperature, Humidity, light, soil moisture and watering system to the plant. In this proposed system temperature controlling controller is used to take current temperature as input by using temperature sensor and its deviation from user set data. The temperature is controlled by the speed of fan. This algorithm is same for all other parameters. In this research the set value of different sensors is selected by the owner of the greenhouse according to the basis of growing plant condition. This system will enhance the capability of fuzzy logic control systems in case of process automation and potentiality.Simulation using MATLAB is used to achieve the designed goal.
\end{abstract}

\section{KEYWORDS}

Fuzzy logic, Green house, Sensor, MATLAB Simulink, Machine learning

\section{INTRODUCTION}

A greenhouse is a build-up environment that promotes all the factors of improving the agriculture performance. It is generally consisting of four parts shown in Figure 1 [1] i.e. Cover of the surface, soil, plant and internal air. Surface separates the outside environment from inside environment. It protects the internal plants from the outsides bad weather and diseases. It can be consisting of polyethylene of glass. The internal air is the more essential part or components of the greenhouse. It is influenced by the external temperature and relative humidity. The soil has to be considered in this section because of having absorbance and diffusion property of thermal heat. The plants have the important role in heat and water balances of the process. In this paper the three components i.e. internal air, soil, surface will be discussed. Control system is a device, a set of devices that controls, manages, commands the other devices or system. Industrial controlling system are used for the production of industrial equipment or machine. This control system is designed, developed and implemented according to the specification of equipment or machine. The performance of the controller depends on the all element included into these systems designed, developed and implemented according to the specification of equipment or machine. The performance of the controller depends on the all element included into this system [2]. Computational intelligence system is an intelligent information processing in different sector of computer science. The fuzzy systems are one of the most intelligent system. According to tradition logic binary sets have two values true or false, where fuzzy logic variable contains the 
truth value in the degree of range from 0 to 1 . Fuzzy logic has been applied to handle the partial truth concept. The partial truth ranges from completely truth to completely false. Fuzzy logic emulates the logic as like human thought which is much less inflexible than calculating computer generally perform. An intelligent control system involves large number of inputs [3]. By using different types of rules fuzzy logic has been upgrade the computer to think like a human. Using fuzzy logic algorithm, system has been able to think, enable machine to understand and response the human concept i.e. hot, very hot, cold, very cold, normal etc. [4]. Because of being a building and occupant thermal interaction for long duration, greenhouse dynamic equation for interior air temperature has taken in consideration. Fuzzy logic interaction with microcontroller for climate controlling has been proposed in [3]. S.D.Dhamakale et al. proposed that for temperature and humidity control. Fuzzy logic controller for controlling the geothermal of greenhouse has been proposed by FatenGouadria et al [4]. Temperature humidity, sunlight intensity, wind speed and direction has included by A. Sriraman et al. Another research work to control temperature, relative humidity, light controlling, Irrigation and nutrient solution control, Carbon Dioxide $(\mathrm{CO} 2)$ control has been proposed in [5]. Their proposed system mainly optimizes heat and energy of greenhouse and consume water. Climate controlling inside the green house by using fuzzy logic has been proposed in [6]. They implemented the system by using MATLAB for temperature and humidity controland linguistic variables for sensors and actuators. Low cost fuzzy logic control and web monitoring system has been implemented by C.R Algarin et al. [7]. In this system Arduino platform is used to monitor the system with fuzzy logic. Carlos Robles algarin et al. proposed a web page that is designed to monitor the climatic condition of the greenhouse. Fuzzy Logic Controller (FLC) prototype has been proposed by P. Javadikia et.al [3] which is simulated on MATLAB.A. Hilali also proposed a greenhouse climate control system i.e. Temperature and moisture controller system [8]. An approach to control greenhouse based on fuzzy has been proposed by R.Caponetto t et al. [9] Heat loss in the greenhouse system and temperature controlling by balancing energy of greenhouse has been controlled by intelligent system[10] . Fuzzy logic based climate control a wireless data monitoring system has been implemented by M. Azaza et. Al [11]. They proposed a system of smart greenhouse system to control both the temperature and humidity of a system to promote a comfortable microclimate for plant growth. They also enhance a platform for data routing and logging to monitor wireless data. Fuzzy logic based climate controlling proposed system has been focused by RafiuddinSyam et al. They monitor the climate, environment of the greenhouse system when watering [12] the plants and also monitoring and applied a fuzzy logic for the change of humidity and temperature after watering. Self-tuning fuzzy logic based PID controller has been implemented by Mahdi Heidari et. al. They proposed a model by using both controller i.e. fuzzy and PID. Here they have showed PID controller [13] and Fuzzy controller to compare the performance of the proposed climate controlling system. Satyajit Ramesh Potdar et.al proposed a system to monitor air temperature $[14,15,16,17]$ of greenhouse. Energy balance principle-based greenhouse system has been proposed for improving the complexity and dynamic of environment.

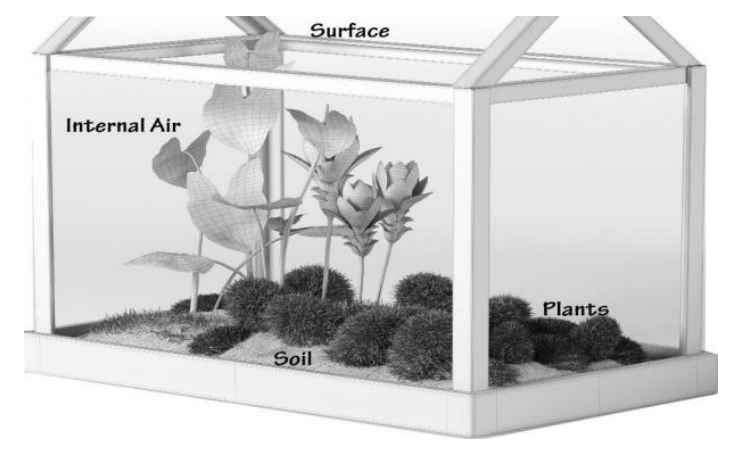

Figure 1. A basic view of Greenhouse system. 


\section{Fuzzy Controller for The Proposed Greenhouse System (GhS)}

Figure 2 represents the block diagram of the proposed system.In this system five different sensors, temperature, humidity, rain, moisture and light intensity is used to measure the current condition of the plant. The set value is included in the fuzzy set through the membership function. Different fuzzy rules are added to the controller to give the knowledge about the system. This system measures current temperature by using different sensors. All the values are taken by the controller. With the help of this measuring value and given set value the controller takes a decision to speedup or speed down or OFF the devices to control the suitable environment inside the greenhouse. For example, if the temperature is raised from the set-up temperature then the controller speeds up the cooler proportion to the raising temperature. If humidity is decreased, then the controller speeds up the vapor supplier to supply more vapor to rise the humidity. If humidity is increased, then the controller speeds up the heater supplier to supply more heat to less the humidity. A sample greenhouse controlling system is shown in Figure 3.

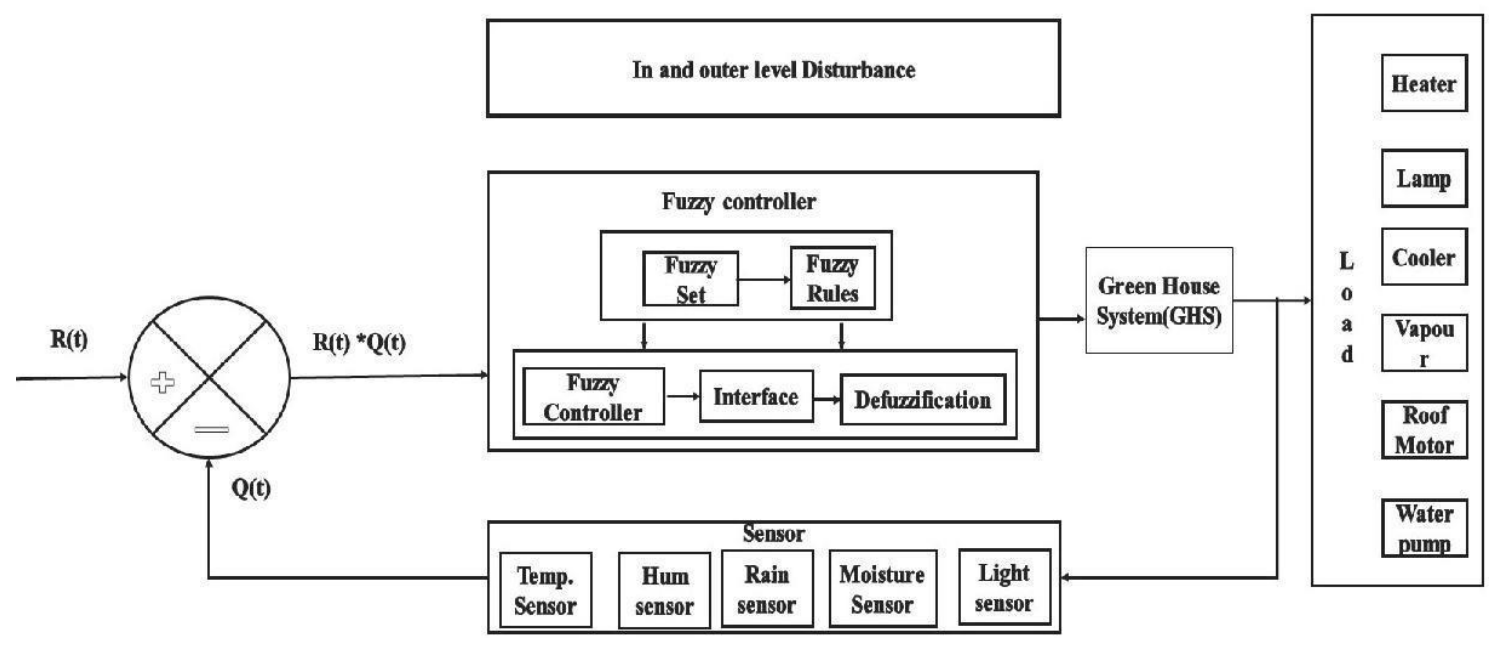

Figure 2. Block diagram of proposed Greenhouse system

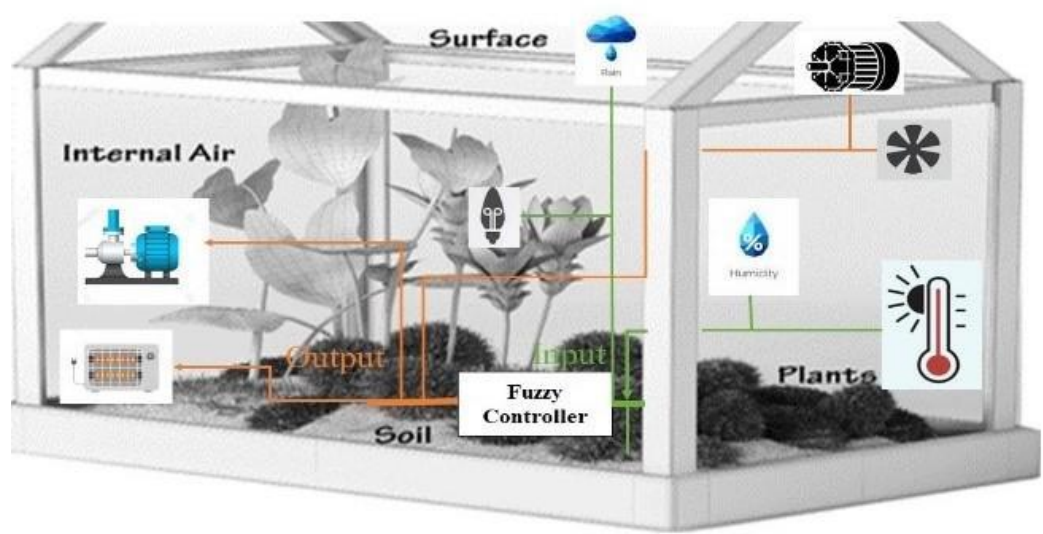

Figure 3. Greenhouse controlling system. 


\section{Mathematical Model Of Greenhouse System}

Because of being a building and occupant thermal interaction for long duration, greenhouse dynamic equation for interior air temperature has taken in consideration. For greenhouse the dynamic equation [18] for heat balance is

$$
\rho C_{p} V \frac{\partial T_{\text {in }}}{\partial t}=Q^{\text {short }}-Q^{\text {conv,cond }}-Q^{\text {infilt }}-Q^{\text {long }}+Q^{\text {heater }}-Q^{\text {ventilation }}
$$

$Q^{\text {short }}=$ Short wave radiation.

$Q^{\text {conv, } \text {,ond }}=$ convection and conduction heat transfer rate

$Q^{\text {infilt }}=$ Heat loss due to the infiltration

$Q^{\text {long }}=$ long wave radiation

$Q^{\text {heater }}=$ thermal energy provided by the heating system

$Q^{\text {ventilation }}=$ thermal energy loss from the cooling system.

The model operates within from $-10^{\circ} \mathrm{C}$ to $45^{\circ} \mathrm{C}$ temperature range. User can set desired temperature to control the environment inside the greenhouse. The fuzzy membership function is design to smooth controlling of temperature. Here input variable is the temperature sensor that measure current temperature and with the help of set and current temperature, the controller decide a value to drive the cooler with desired speed. Temperature of a greenhouse randomly change due to the disturbance of climate change and can be controlled by maintaining uniform distribution of climate variable [19]. Heat can be balanced by considering the following equation in above. The short-wave radiation absorbed by greenhouse system can be calculated by the following equation [20].

$$
Q^{\text {short }}=\tau_{c} \alpha_{c} S I
$$

Where $\alpha_{c}$ is the cover absorptivity of solar radiation, $\tau_{c}$ is the cover transmittance, $\mathrm{S}$ is the surface area $\left(\mathrm{m}^{2}\right)$, and I is the solar radiation $\left(\mathrm{Wm}^{-2}\right)$.

$$
Q^{\text {conv }, \text { cond }}=U S\left(T_{\text {in }}-T_{\text {out }}\right)
$$

Where, $T_{\text {out }}$ represents the outside temperature of the system, $T_{\text {in }}$ represents the measuring temperature by the temperature sensor and $U$ is the overall heat transfer coefficient through the greenhouse walls $\left(\mathrm{Wm}^{-2} \mathrm{~K}^{-1}\right)$ and $\mathrm{S}$ represents the surface area of the system. The heat loss due to the infiltration through the greenhouse was calculated using the equation [18] in (4).

$$
Q^{\text {infilt }}=\rho_{a} C_{a} R \frac{T_{\text {in }}-T_{\text {out }}}{3600}
$$

The greenhouse system absorbed the long wave radiation is calculated by the equation in 5

$$
Q^{\text {long }}=h_{0} S\left(1-\tau_{c}\right)\left(T_{\text {in }}-T_{\text {sky }}\right)
$$

Where, $T_{s k y}$ is the sky temperature that is suggested by Swinbank [18]. The thermal energy provided by the heating system is defined as

$$
Q^{\text {heater }}=\frac{N_{h} R_{h}}{S}
$$


Where, $N_{h}$ is the number of heaters, $R_{h}$ is the capacity of the heating system $\left(\mathrm{Wm}^{-2}\right)$. The thermal energy loss [18] from the cooling system is represented by the following equation.

$$
Q^{\text {ventilation }}=C_{a} R_{v}
$$

Table 1. Sub System's Parameters Value for Temperature Balance of Greenhouse.

\begin{tabular}{|c|c|c|c|}
\hline Parameter & Description & Unit & value \\
\hline$\tau_{c}$ & cover transmittance & N/A & 0.85 \\
\hline$\alpha_{c}$ & cover absorptivity & N/A & 0.1 \\
\hline $\mathrm{S}$ & surface area & $\mathrm{m}^{2}$ & 5 \\
\hline $\mathrm{I}$ & solar radiation & $\mathrm{Wm}^{-2}$ & 2 \\
\hline$\rho_{a}$ & heater output & $\mathrm{W}$ & 1.137 \\
\hline$C_{a}$ & air density & $\mathrm{Kgm}^{-3}$ & 1005 \\
\hline $\mathrm{R}$ & number of air changes per hour & $\mathrm{m}^{3} \mathrm{~S}^{-1}$ & 2 \\
\hline$T_{\text {in }}$ & interior air temperature & ${ }^{\circ} \mathrm{C}$ & \\
\hline$T_{\text {out }}$ & outside air temperature & ${ }^{\circ} \mathrm{C}$ & -10 \\
\hline $\mathrm{U}$ & $\begin{array}{c}\text { overall heat transfer coefficient } \\
\text { through the greenhouse walls }\end{array}$ & $\mathrm{Wm}^{-2} \mathrm{C}^{-1}$ & 1.137 \\
\hline $\mathrm{V}$ & building volume & $\mathrm{m}^{3}$ & 20 \\
\hline$N_{h}$ & number of heaters & $\mathrm{N} / \mathrm{A}$ & 1 \\
\hline$R_{h}$ & capacity of the heating system & $\mathrm{Wm}^{-2}$ & 10 \\
\hline$R_{v}$ & ventilation rate & $\mathrm{m}^{3} \mathrm{~S}^{-1}$ & 4 \\
\hline
\end{tabular}

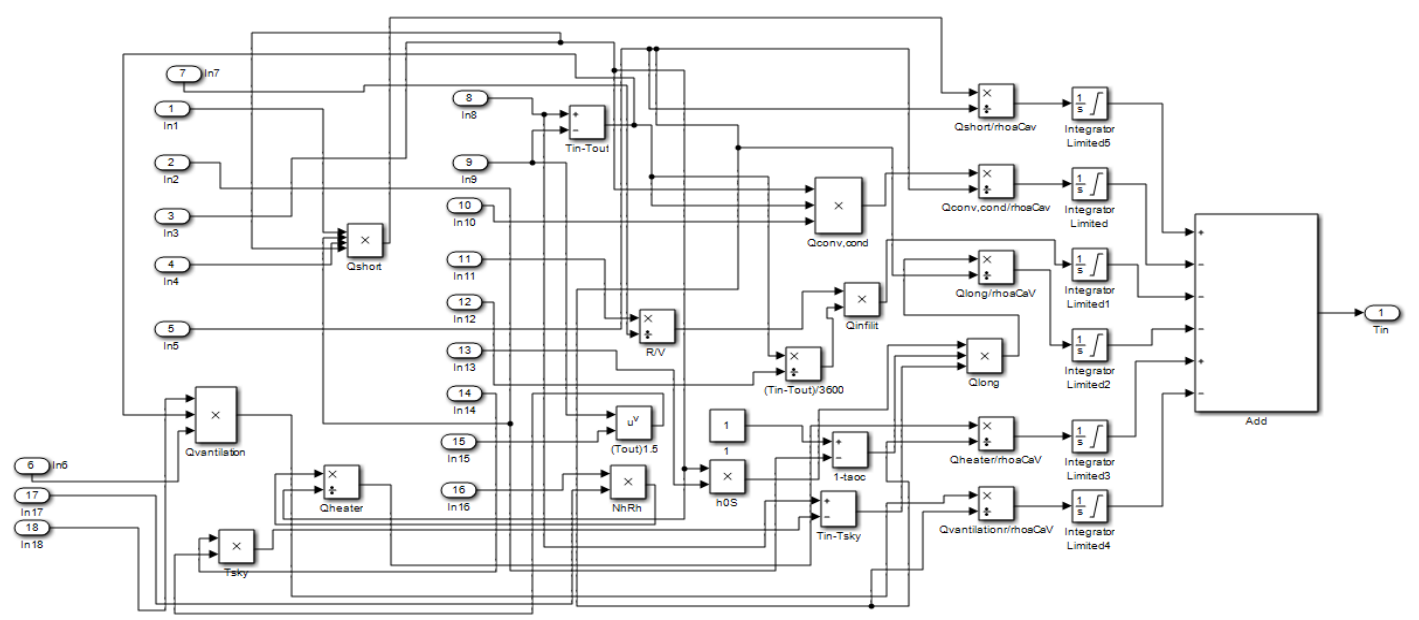

Figure 4. Sub System for temperature balance of Greenhouse

The relative humidity of the climate is amount of water in the air. For greenhouse to control humidity specific parameter are considered as the following equation [21,22,23,24].

$\rho v_{i} \frac{\partial x_{i}}{\partial t}=P A V(\mathrm{a} \alpha+G(0))\left(x_{i}-x_{o}\right)+E+f o g(8)$

Here, $\rho=$ air density

$v_{i}=$ Greenhouse volume

$\mathrm{A}=$ vent area

$\mathrm{V}=$ wind Speed

$\mathrm{a}, \mathrm{G}(0)=$ ventilation parameter 
$\alpha=$ vent opening

$x_{o}=$ outside absolute humidity

$x_{i}=$ inside absolute humidity.

$\mathrm{E}=$ plant transpiration rate

fog= vapor generation by the fog system

Table 2. Subsystem's parameters value for humidity balance of Greenhouse.

\begin{tabular}{|c|c|c|c|}
\hline Parameter & Description & unit & value \\
\hline$v_{i}$ & Greenhouse volume & $\mathrm{m}^{3}$ & 24 \\
\hline $\mathrm{A}$ & vent area & $\mathrm{m}^{2}$ & 4 \\
\hline $\mathrm{V}$ & wind Speed & $\mathrm{kms}^{-1}$ & 20 \\
\hline $\mathrm{a}, \mathrm{G}(0)$ & ventilation parameter & $\mathrm{N} / \mathrm{A}$ & 1.1 \\
\hline$\alpha$ & vent opening & N/A & 0.1 \\
\hline$x_{0}$ & $\begin{array}{c}\text { outside absolute } \\
\text { humidity }\end{array}$ & $\mathrm{N} / \mathrm{A}$ & 50 \\
\hline$x_{i}$ & $\begin{array}{c}\text { Inside absolute } \\
\text { humidity. }\end{array}$ & $\mathrm{N} / \mathrm{A}$ & 40 \\
\hline fog & $\begin{array}{c}\text { vapor generation by } \\
\text { the fog system }\end{array}$ & $\mathrm{m}^{3} \mathrm{~s}^{-1}$ & 0.03 \\
\hline $\mathrm{E}$ & $\begin{array}{c}\text { plant transpiration } \\
\text { rate }\end{array}$ & $\mathrm{Cmday}^{-1}$ & 1.137 \\
\hline $\mathrm{P}$ & air density & $\mathrm{kgm}^{-3}$ & \\
\hline
\end{tabular}

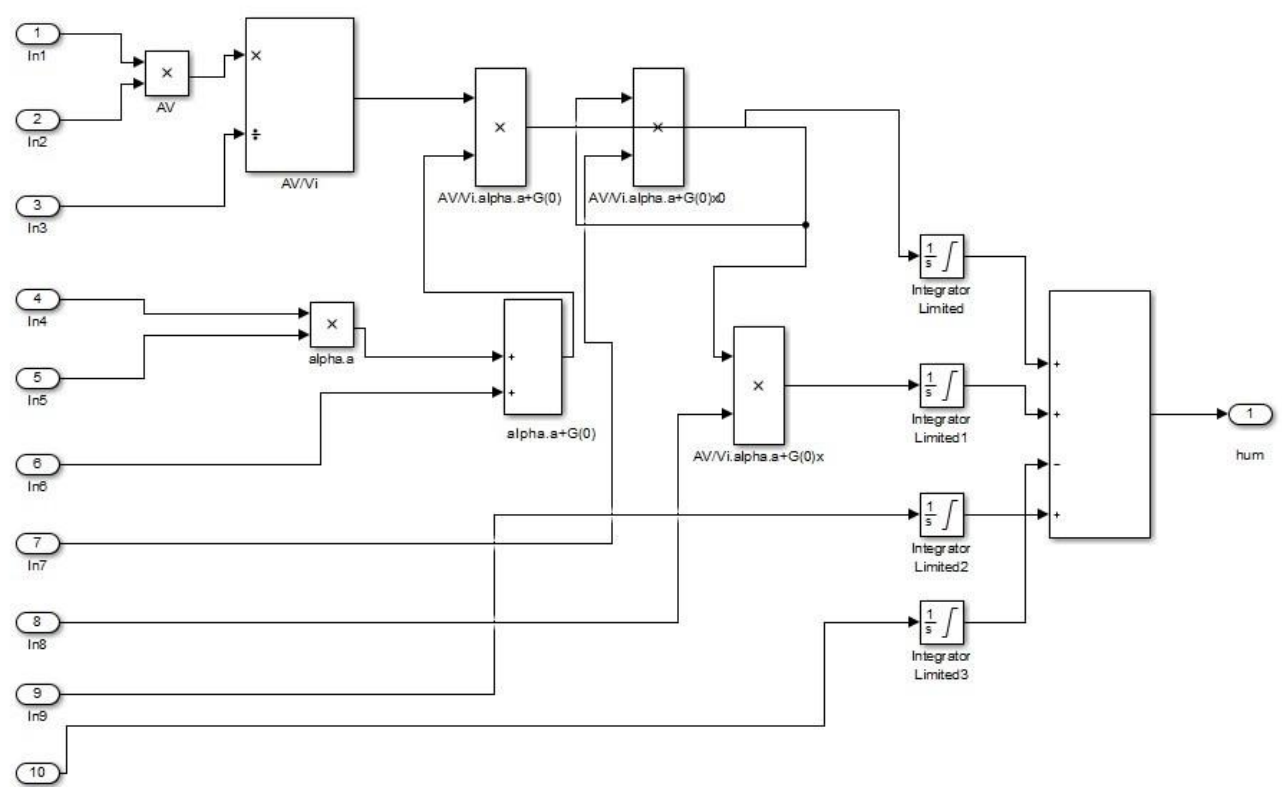

Figure 5. Design of Humidity Control System for Greenhouse

Light intensity measurement is the one of the vital parameters in green house system. The intensity of light can be measured by the light dependent resistor (LDR). The resistance of LDR depends on the illumination of light $(\mathrm{E})$ and the material used for making LDR sensor. The CDS (Cadmium sulphide) based LDR's manufacturing value is varied from 0.7 to 0.9 . The resistance of LDR follows the below equation. 


$$
\mathrm{R}=\mathrm{A} \times E^{a}
$$

Here $\mathrm{R}$ is the resistance, $\mathrm{A}$ and a are constant and $\mathrm{E}$ is the illumination of light. In this model the parameter's value used for measuring the resistance and sensor value are focused on the Table 3.

Table 3. Sub System's Parameters Value for Light Intensity Measure of Greenhouse.

\begin{tabular}{|c|c|c|c|c|}
\hline Parameter & Description & Unit & \multicolumn{2}{|c|}{ Value } \\
\hline $\mathrm{R}$ & Resistance & ohm & & \\
\hline $\mathrm{a}$ & $\begin{array}{c}\text { Constant } \\
\text { value for } \\
\text { manufacturing }\end{array}$ & N/A & \multicolumn{2}{|c|}{0.9} \\
\hline $\mathrm{E}$ & Illumination & (lux) & $\begin{array}{l}\text { Very Bright Summer } \\
\text { Day } \\
\text { Full Daylight } \\
\text { Overcast Summer Day } \\
\text { Very Dark Day } \\
\text { Twilight } \\
\text { Full Moon }\end{array}$ & $\begin{array}{l}100,000 \text { Lux } \\
10,000 \text { Lux } \\
1,000 \operatorname{Lux} \\
100 \operatorname{Lux} \\
10 \operatorname{Lux} \\
<1 \operatorname{Lux}\end{array}$ \\
\hline A & Constant & N/A & \multicolumn{2}{|c|}{10} \\
\hline
\end{tabular}

According to the above parameter and its value is used to develop a subsystem which is focused on the Figure 6.

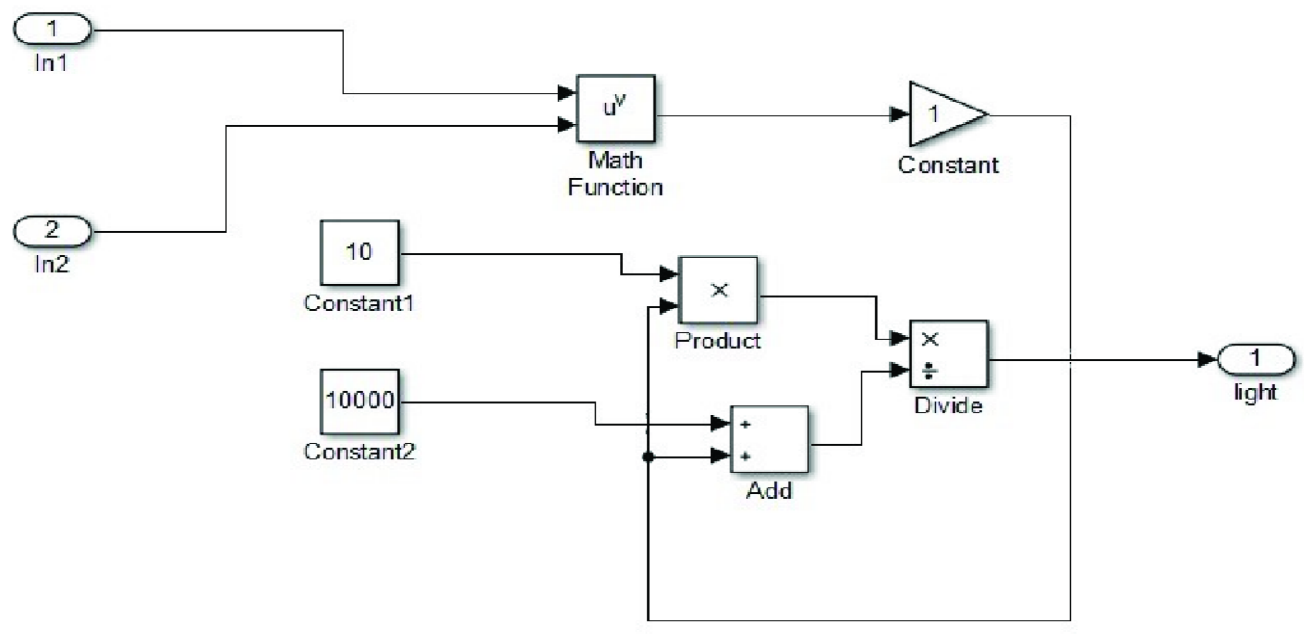

Figure 6. Subsystem of light intensity measurement

Sensing of rain is very emergent for greenhouse system because of using the rain water for plant to increase the moisture of soil according to required value. For this reason, rain sensor is used to measure rainfall. A rain sensor plays a vital rule to detect the rain. The rain sensors working procedure is same as comparator circuit. The designing parameter of rain sensor acting process in describe in below Table 4 . The equation of finding degree of rainfall is described in below.

$$
V_{\text {out }}=\frac{V_{c c} R_{2}}{R_{1}+R_{2}}-V_{\text {in }}
$$

Table 4. Sub System's parameters value for rainfall value measure of Greenhouse. 


\begin{tabular}{|c|c|c|c|}
\hline $\begin{array}{c}\text { Parameter for } \\
\text { Rain }\end{array}$ & Description of parameters & Unit & Value \\
\hline$V_{\text {out }}$ & Result of rain sensor & Volt & \\
\hline$V_{\text {in }}$ & Sensing value & volt & 2 \\
\hline$R_{2}$ & Variable resistor & Kilo ohm & 10 \\
\hline$V_{c c}$ & Supply voltage & volt & 10 \\
\hline$R_{1}$ & Fixed Resistor & Kilo ohm & 1 \\
\hline
\end{tabular}

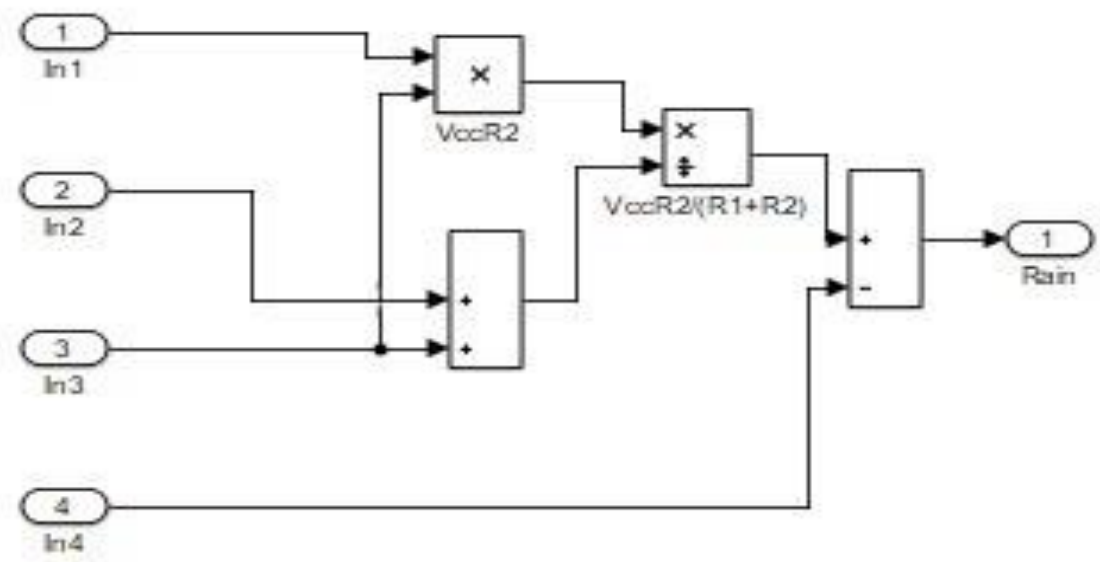

Figure 7. Subsystem for rain intensity measurement

Sensing of amount of water present in soil is very important for plant to rise inside the greenhouse system. For this purpose, Expert system moisture sensor is needed to monitor the water amount needed for plant. The Soil moisture sensor follows the below equation.

$$
\varepsilon_{b}{ }^{1 / 2}=x_{a} \varepsilon_{a}{ }^{1 / 2}+x_{m} \varepsilon_{m}{ }^{1 / 2}+x_{w} \varepsilon_{w}{ }^{1 / 2}
$$

Dielectric sensor only senses the bulk dielectric permeability of soil not water contents.

The relationship between bulk dielectric constant and soil water content is used to measure accuracy.

Where, $\varepsilon$ is used to represent the relative dielectric permittivity, volume fraction is represented by $x$ and the subscripts $\mathrm{b}, a, m$, and wrepresent the properties of material i.e. bulk, air, mineral, and water respectively. The permittivity of air is 1 . The permittivity of soil minerals can range from 3 to 16 but a value of 4 is often used. We can substitute for $x_{a}$ the expression $1-x_{w}-x_{m}$ and for $x_{m}$ the ratio of bulk to particle density of the soil, $\frac{\rho_{b}}{\rho_{s}}$

Table 5. Subsystem's parameters value for soil moisture Measure of Greenhouse.

\begin{tabular}{|l|c|l|}
\hline Quantity & Symbol & Nominal Value \\
\hline Bulk Permittivity & $\varepsilon_{b}$ & 10 \\
\hline Water Permittivity & $\varepsilon_{w}$ & 80 \\
\hline Mineral Permittivity & $\varepsilon_{m}$ & 4 \\
\hline Bulk Density & $\rho_{b}$ & 1.3 \\
\hline Particle Density & $\rho_{s}$ & 2.65 \\
\hline
\end{tabular}




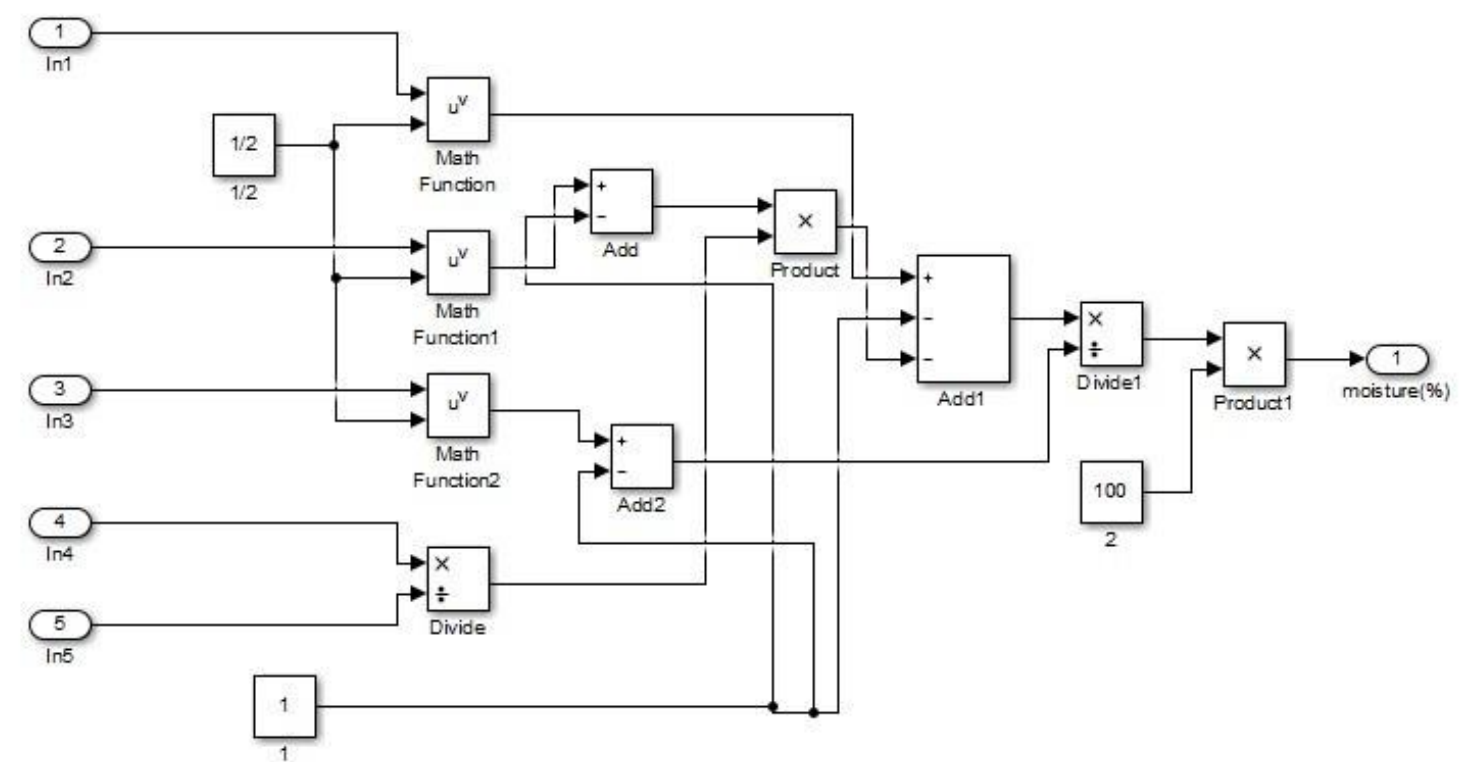

Figure 8. Subsystem for Soil moisture measurement

\section{Modelling Of Fuzzy ConTroller}

A proposed GHS with fuzzy controller has showed in Figure 2. This system is designed to control temperature, humidity, light, moisture and water pump of a greenhouse. The algorithm is designed based on fuzzy logic to smooth controlling every parameter of greenhouse. This algorithm is used to design the fuzzifier,defuzzifier according to the control strategy of the processing plant to ensure quality.

\subsection{Temperature controlling}

The greenhouse parameter temperature is controlled by using fuzzy logic. This designing system is controlled at -10 to 45 degree centigrade. This temperature is divided into five sections and defined as membership function. This designing membership function is showed in Table 6.

Table 6. Membership function of current Temperature.

\begin{tabular}{|c|c|}
\hline Membership function & Range (Degree Centigrade) \\
\hline Very cold (VC) & -10 to 2.5 \\
\hline Cold(C) & -1 to 15 \\
\hline Normal (NOR) & 12 to 27 \\
\hline HOT & 25 to 36 \\
\hline Very Hot (VHOT) & 32 to 45 \\
\hline
\end{tabular}

Temperature is mainly controlled by the heater. When the heater in ON or OFF state depending on the current temperature of the room, Fuzzy controller helps to speed up the heating supply where the traditional logic has only OFF and ON state. The output variable heater has 3 membership function OFF, LOW and HIGH. 
Table 7. Membership function of Heater.

\begin{tabular}{|c|c|}
\hline Membership Function of Heater & Point of value \\
\hline OFF & $0,0,2.5$ \\
\hline LOW & $0,2.5,5$ \\
\hline HIGH & $2.5,5,5$ \\
\hline
\end{tabular}

When the temperature will rise from the set temperature then the cooler will automatically ON and will speed up automatically. For cooler there are 3 membership function, OFF, LOW and HIGH. The fuzzy controller takes a decision what type of operation will happen to control the temperature.

\subsection{Controlling Humidity}

Relative Humidity is measured by the percentage of water vapour in air and in relation to the amount of holding at a given temperature. The Humidity that gives comfortable atmosphere depends on temperatures, indicated in below. This designing five membership functions from the range of 0 to 100 percentage of humidity that is showed in Table 9 .

Table 8. Membership function of Humidity

\begin{tabular}{|c|c|}
\hline Membership function & Range (\%) \\
\hline Very Low(VL) & 0 to 20 \\
\hline Low(L) & 10 to 40 \\
\hline Normal(NOR) & 30 to 55 \\
\hline HIGH(H) & 50 to 70 \\
\hline Very High(VHIGH) & 60 to 100 \\
\hline
\end{tabular}

When the humidity will rise from the set humidity then the vapor supplier will automatically ON and will speed up automatically. For vapor supplier there are 3 membership function, OFF, LOW, HIGH. The fuzzy controller takes a decision what type of operation will happened to control the humidity.

Table 9. Membership function of vapor.

\begin{tabular}{|c|c|}
\hline Membership Function of Vapor & Point of value \\
\hline OFF & $0,0,2.5$ \\
\hline LOW & $0,2.5,5$ \\
\hline HIGH & $2.5,5,5$ \\
\hline
\end{tabular}

\subsection{Light controlling}

The light intensity of the greenhouse has been controlled using fuzzy controller. The intensity measured by light sensor LDR and the value range from 0 to 10 . The intensity level will have increased then the output value will have increased. To control proper intensity three membership function LOWLIGHT, NORLIGHT and HIGHLIGHT have declared. And the range of each membership function has given on the Table 10.

Table 10. Membership function of Light Intensity.

\begin{tabular}{|c|c|}
\hline Membership function of light sensor & Range (Light Intensity) \\
\hline LOWLIGHT & 0 to 3.5 \\
\hline NORLIGHT & 2.8 to 7.24 \\
\hline HIGHLIGHT & 6.3 to 10 \\
\hline
\end{tabular}


The light controlling device Lamp will be derived by the controller and lamp's intensity will increase and decreased by the value of three membership function.

\subsection{Moisture controlling}

The moisture of the soil is most important for plants. In the greenhouse system the moisture of the soil is controlled by using fuzzy logic. The three-membership function have declared to the controller in the range between 0 and 50 and the declared membership function is DRY, NORMAL, WET. The value is selected as the Table 11 in below.

Table 11. Membership function of Moisture.

\begin{tabular}{|c|c|}
\hline Membership function of moisture & Range (Moisture value) \\
\hline DRY & 0 to 20 \\
\hline NORMAL & 12 to 35 \\
\hline WET & 28 to 50 \\
\hline
\end{tabular}

To control the moisture, the water pump motor is used. The motor serves water at three condition i.e. OFF, LOW and HIGH. This water pump will ON or OFF depend on the rain sensor. The design value of input moisture function has showed in Table 12.

Table 12. Membership function of Water pump.

\begin{tabular}{|c|c|}
\hline Membership Function of water pump & Point of value \\
\hline OFF & $0,0,2.5$ \\
\hline LOW & $0,2.5,5$ \\
\hline HIGH & $2.5,5,5$ \\
\hline
\end{tabular}

The rain sensor detects the current rain status and fuzzy control system select three membership function NRAIN, LIGHTRAIN, HEAVY RAIN. If the rain present, then the rain water will be supplied to the soil and the main water pump will not ON. The rainfall-based input membership function has been given out at Table 13 .

Table 13. Membership function of Rain Sensor.

\begin{tabular}{|c|c|}
\hline Membership function of Rain sensor & Range (Rain intensity) \\
\hline NORAIN & 0 to 3.5 \\
\hline NORMALRAIN & 2.8 to 7.3 \\
\hline HEAVYRAIN & 5.8 to 10 \\
\hline
\end{tabular}

Rain water will be supplied to the soil if the soil moisture status is dry and the rain water is present. For rain water supply two-member function OFF and OPEN have selected. The roof motor will be $\mathrm{ON}$ or OFF according to the designing rules in fuzzy logic. The output membership function for roof motor has been focused at Table 14. 
International Journal of Fuzzy Logic Systems (IJFLS) Vol.10, No.1, January 2020

Table 14. MembePrship function of Roof Motor.

\begin{tabular}{|c|c|}
\hline Membership function of Roof motor & $\begin{array}{c}\text { Range (Roof motor supply } \\
\text { voltage) }\end{array}$ \\
\hline OFF & 0 to 2 \\
\hline NORMAL & 1.5 to 3.5 \\
\hline HIGH & 3 to 5 \\
\hline
\end{tabular}

\subsection{Rules of greenhouse system}

The rules set up for fuzzy logic-based greenhouse parameter controlling system have shown in Table15. This table contains the fuzzy possible logic for this considering parameter of greenhouse controlling system.

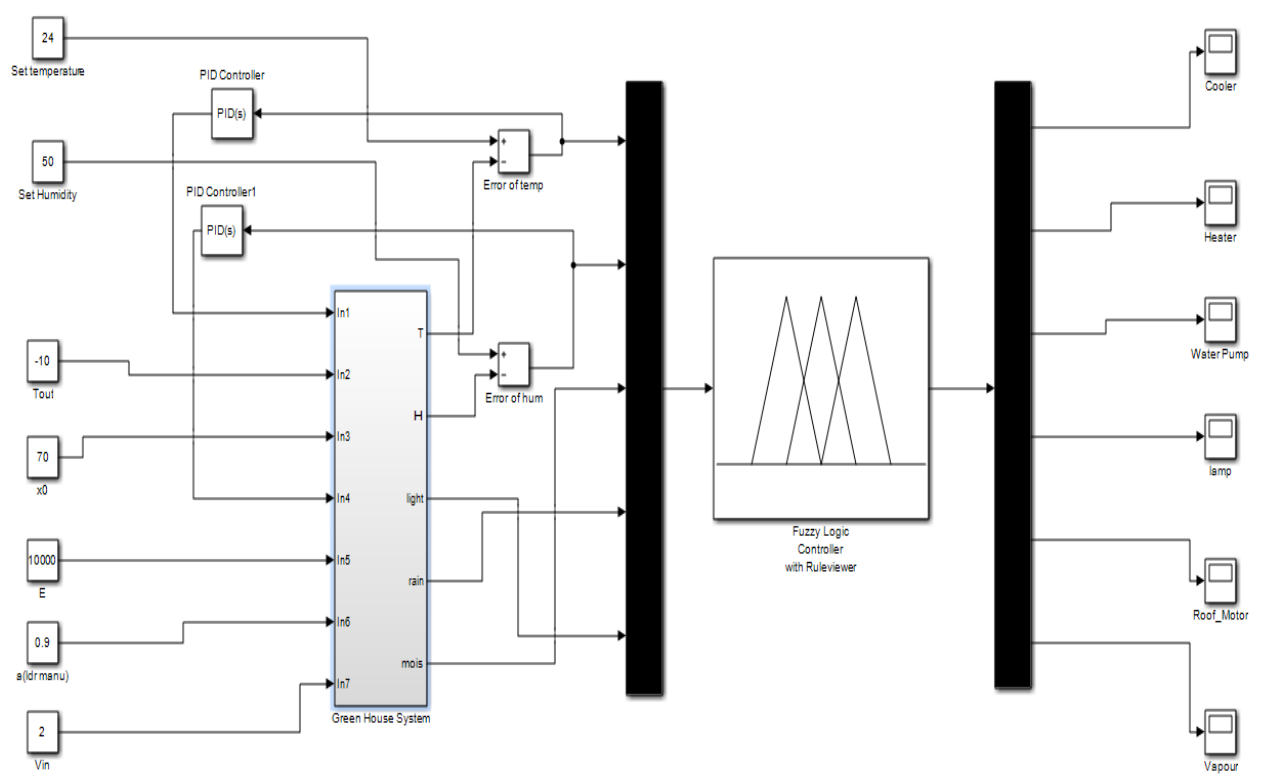

Figure 9. Model of greenhouse system using Fuzzy logic.

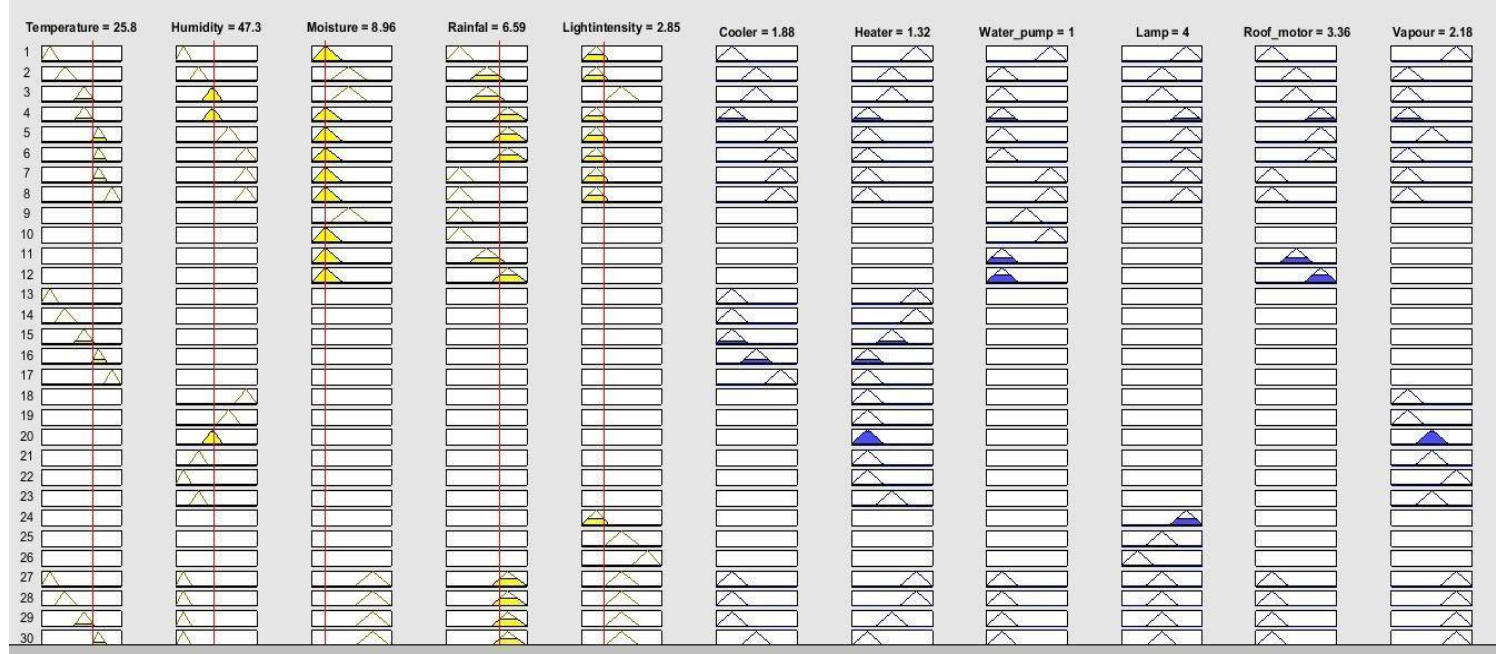

Figure 10. Matlab Rules View. 
Table 14. Rules view of fuzzy logic.

\begin{tabular}{|c|c|c|c|c|c|c|c|c|c|c|}
\hline Temperature & Humidity & Light & Rainfall & $\begin{array}{c}\begin{array}{c}\text { Soil } \\
\text { moisture }\end{array} \\
\end{array}$ & $\begin{array}{c}\text { Heate } \\
\mathbf{r}\end{array}$ & Vapor & Lamp & $\begin{array}{c}\text { Coole } \\
\mathrm{r}\end{array}$ & $\begin{array}{l}\text { Roof } \\
\text { motor }\end{array}$ & Motor \\
\hline $\mathrm{vc}$ & $\mathrm{VL}$ & LOWLIGHT & NRADN & DRY & HIGH & HIGH & LIGHTFULL & OFF & OFF & HIGH \\
\hline $\mathrm{c}$ & $\mathrm{L}$ & NORLIGHT & LIGHTRANN & NORMAL & LOW & LOW & LIGHTDIMMER & OFF & OFF & LOW \\
\hline NOR & $\mathrm{N}$ & HIGHLIGHT & HEAVYRADN & NORMAL & LOW & LOW & LIGHTOFF & OFF & OFF & OFF \\
\hline HOT & $\mathrm{H}$ & LOW & MRAN & WET & OFF & LOW & LIGHTDIMMER & LOW & OFF & OFF \\
\hline VHOT & $\mathrm{VH}$ & LOW & NRAN & WET & OFF & OFF & LIGHTDIMMER & HIGH & OFF & OFF \\
\hline VHOT & $\mathrm{N}$ & HIGHLIGHT & NRAN & DRY & OFF & OFF & LIGHTOFF & HIGH & OFF & HIGH \\
\hline HOT & $\mathrm{N}$ & HIGHLIGHT & NRAIN & WET & OFF & OFF & LIGHTOFF & LOW & OFF & OFF \\
\hline NOR & $\mathrm{N}$ & NORLIGHT & NRAIN & WET & OFF & OFF & LIGHTOFF & LOW & OFF & OFF \\
\hline $\mathrm{c}$ & NONE & NORLIGHT & NRAN & DRY & OFF & OFF & LIGHTOFF & OFF & OFF & HIGH \\
\hline c & NONE & LOWLIGHT & NRAIN & NORMAL & LOW & OFF & LIGHTFULL & OFF & OFF & LOW \\
\hline NOR & $\mathrm{VH}$ & LOWLIGHT & NRAIN & WET & OFF & OFF & LIGHTFULL & OFF & OFF & OFF \\
\hline NOR & $\mathrm{H}$ & NORLIGHT & LIGHTRAIN & DRY & OFF & OFF & LIGHTFULL & OFF & OFF & OPEN \\
\hline NOR & $\mathrm{N}$ & LOWLIGHT & HEAVYRAIN & WET & $\mathrm{OFF}$ & OFF & LIGHTDIMMER & $\mathrm{OFF}$ & OFF & OFF \\
\hline NOR & $\mathrm{N}$ & NORLIGHT & LIGHTRANN & DRY & OFF & OFF & LIGHTOFF & OFF & OPEN & OFF \\
\hline NOR & $\mathrm{N}$ & NORLIGHT & HEAVYRAIN & DRY & $\mathrm{OFF}$ & OFF & LIGHTOFF & OFF & OPEN & OFF \\
\hline NOR & $\mathrm{N}$ & NORLIGHT & NRADN & DRY & OFF & OFF & LIGHTOFF & OFF & OFF & HIGH \\
\hline NOR & $\mathrm{N}$ & NORLIGHT & HEAVYRAIN & WET & OFF & OFF & LIGHTOFF & OFF & OFF & OFF \\
\hline NOR & $\mathrm{N}$ & NORLIGHT & HEAVYRAIN & NORMAL & OFF & OFF & LIGHTOFF & OFF & OPEN & OFF \\
\hline NOR & $\mathrm{N}$ & NORLIGHT & NYRAIN & NORMAL & OFF & OFF & LIGHTOFF & OFF & OFF & LOW \\
\hline
\end{tabular}

\section{RESULT \& DisCUSSION}

This proposed system has been tested in Matlab and for different type of sensing value we get a different output response of controlling device. For a current parameter value the response of device are showed in the Figure 10. In Matlab the simulation run for 10 secs and the controlling output is shown in different scope. In this simulation system the set temperature value was 24 degrees centigrade. The temperature gains and losses by this system give a temperature value of Tin. The error signal between system and set temperature is backed to the input of the system. Then the system's fuzzy controller decides to change the output device such as cooler which is shown in Figure 11. The curve shows that the cooler is stable after the stability of set temperature. In Figure 12, time vs sensor output for heater control is showed. The heater controlling output will be stable after certain period of time. Initially the system's temperature is not matched as the set's temperature so the unstable signal of heater control is showed in Figure 12.

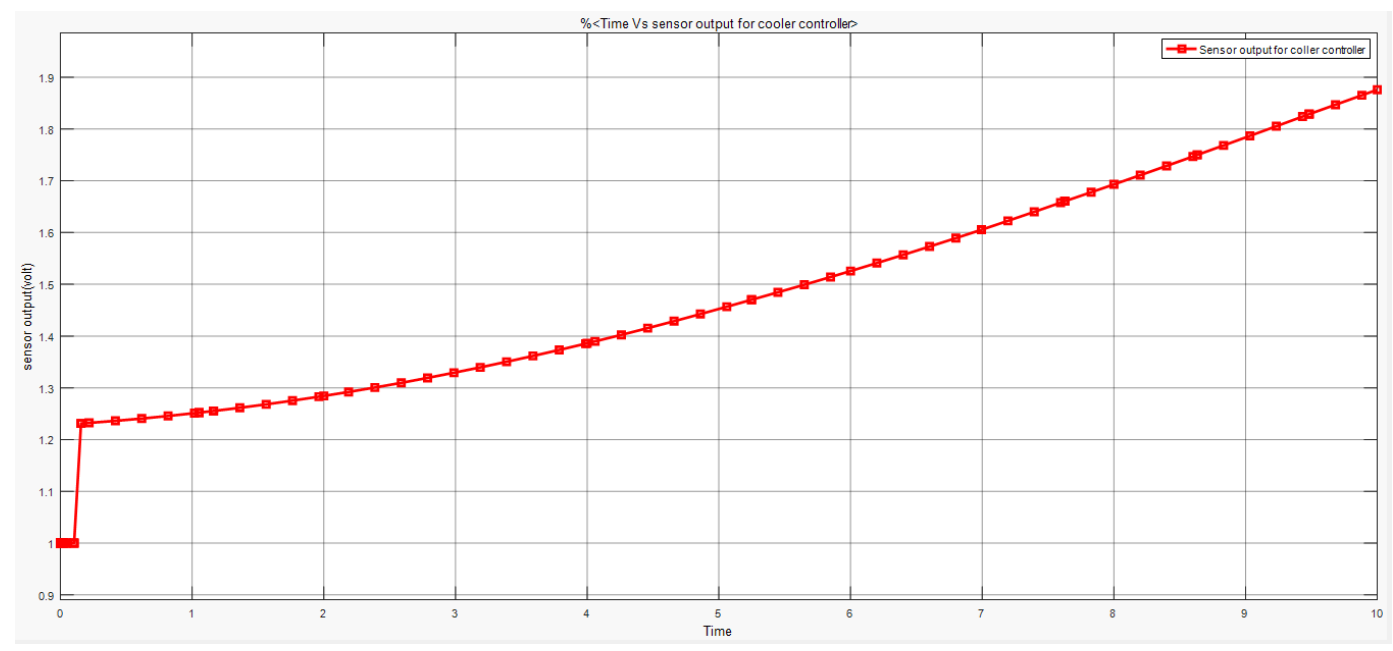

Figure 11. Time vs sensor output for Cooler control 


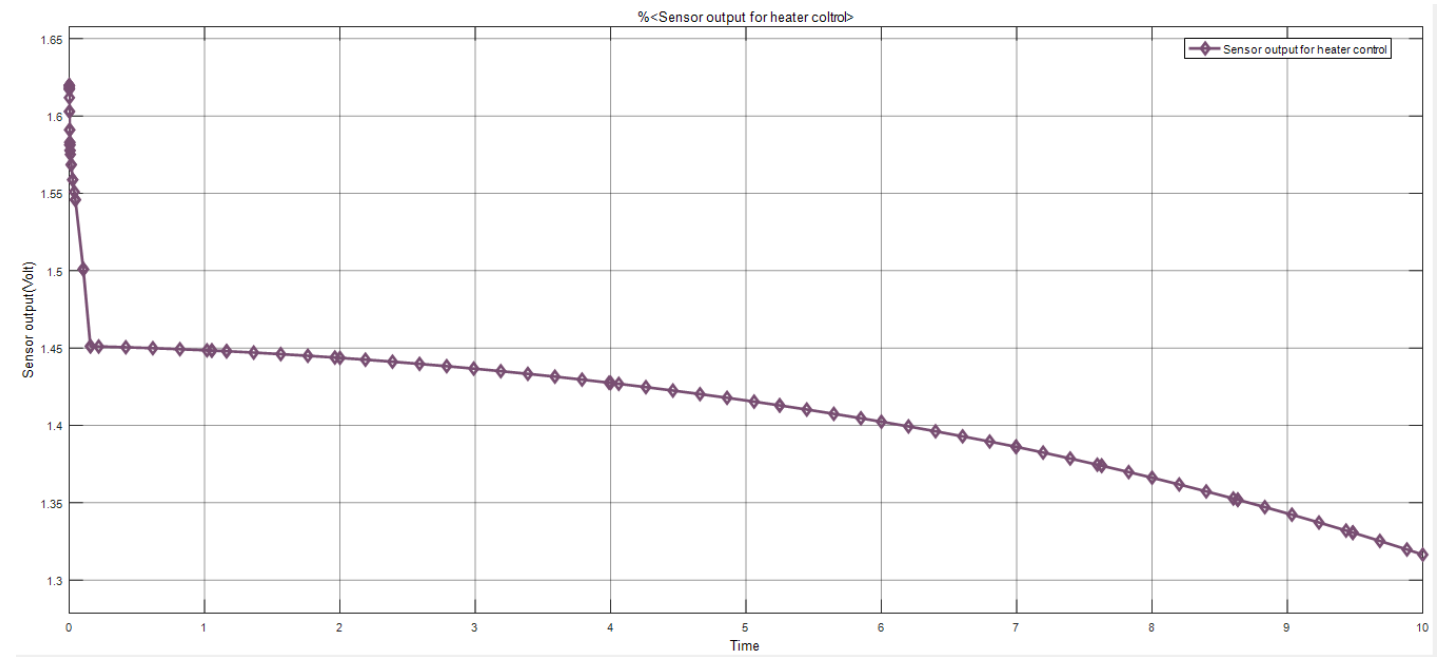

Figure 12. Time vs sensor output for Heater control.

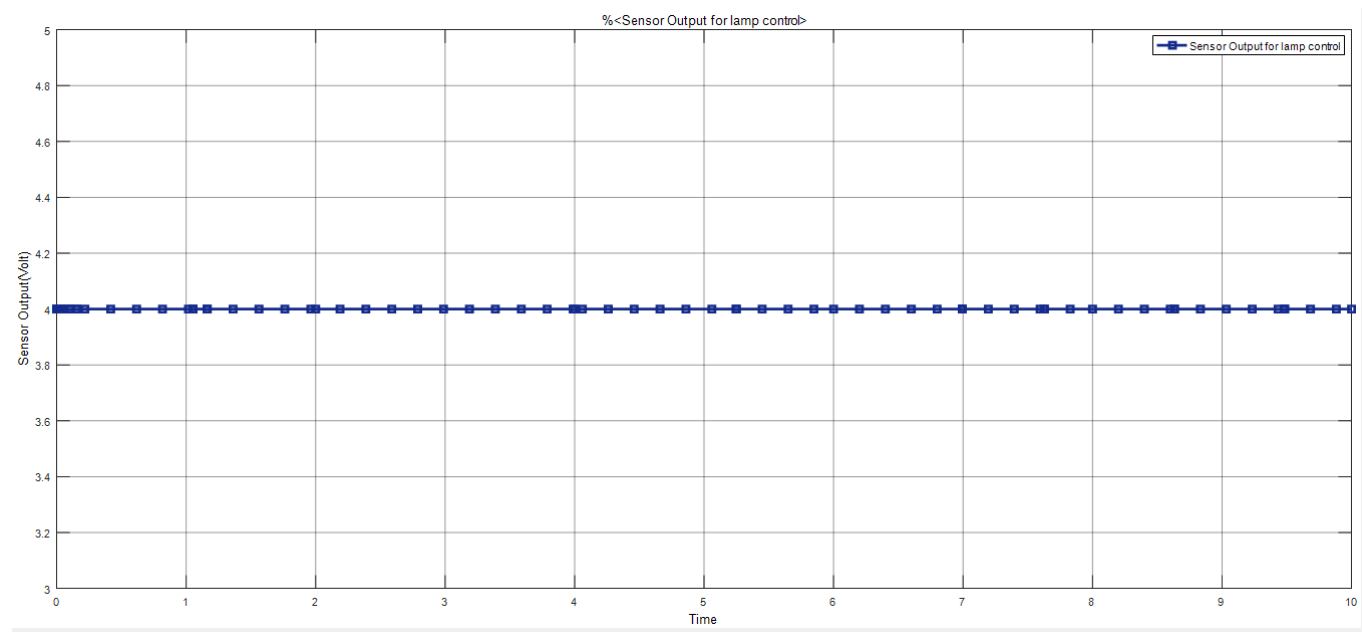

Figure 13. Time vs sensor output for lamp control.

In Figure 13 when the light intensity changes the output device corresponding to this in-put will be changed. In this fig the output data is a straight line so the signal is stable at the start of time. In Figure 14 when the roof motor controlling output is showed, it depends on the two parameters, i.e. Rainfall and moisture sensor value. If these two parameters are true, then the roof motor will On and the sensor output value will be changed. 
International Journal of Fuzzy Logic Systems (IJFLS) Vol.10, No.1, January 2020

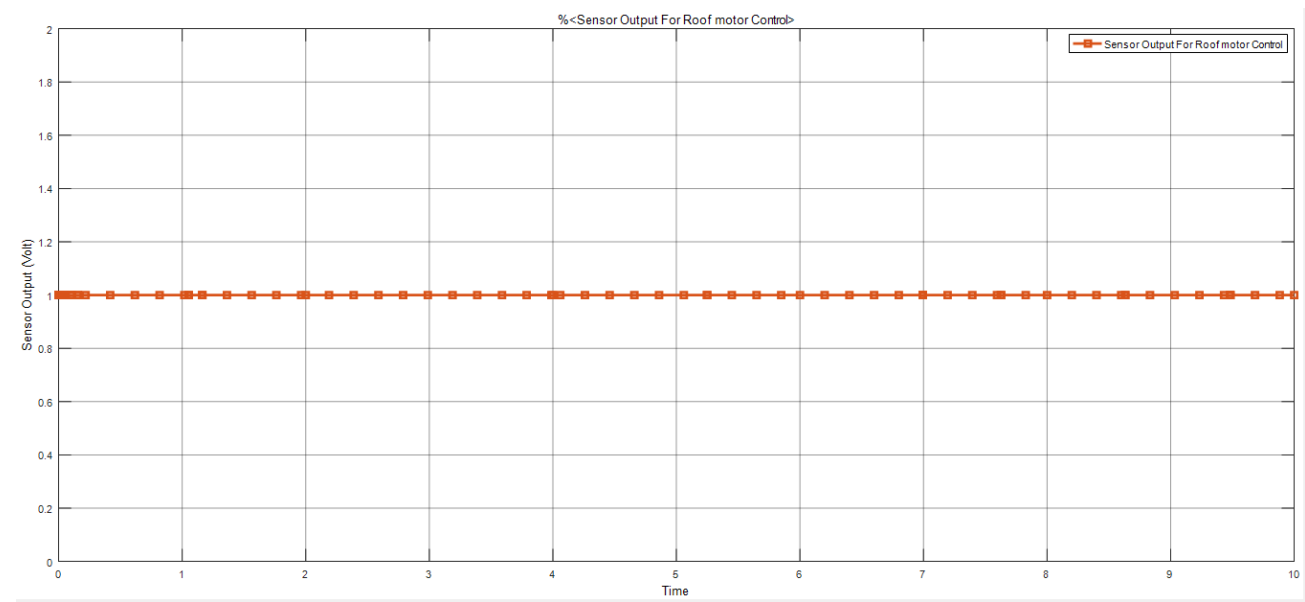

Figure 14. Time vs sensor output for lamp control.

when the humidity will be less than this controlling output is delivered at maximum value which is showed in Figure 15. This curve is also a stable output

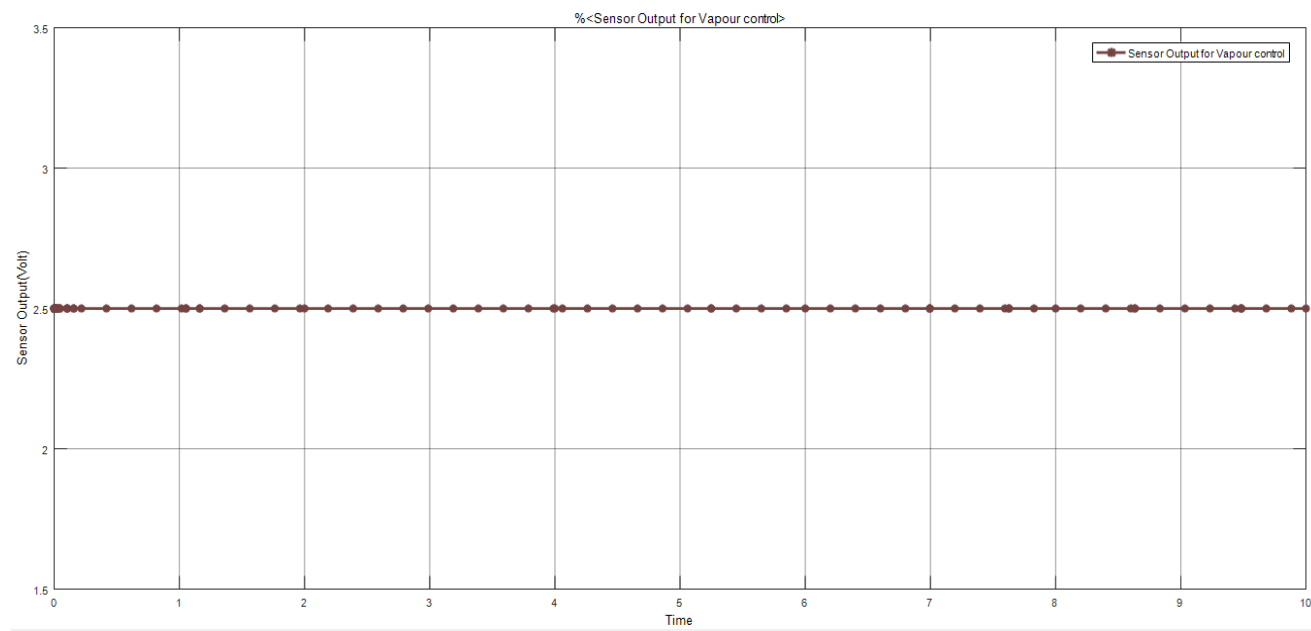

Figure 15. Time vs sensor output for vapor control.

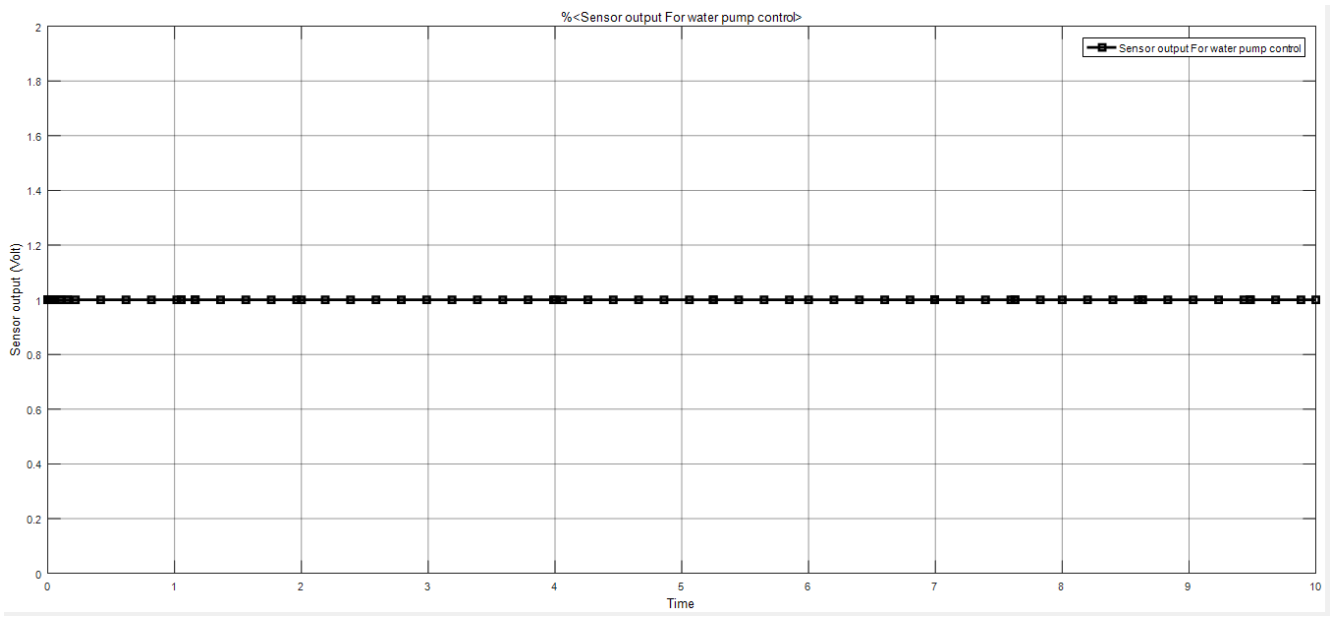

Figure 16. Time vs sensor output for water pump control. 
In Figure 16 the sensor output for water pump control is focused. The water pumps signal depends on the moisture sensor and rainfall sensors. This signal start as a constant value from the start of simulation. In the proposed model of Different parameters of greenhouse system, the balancing output temperature has been showed in Figure 17

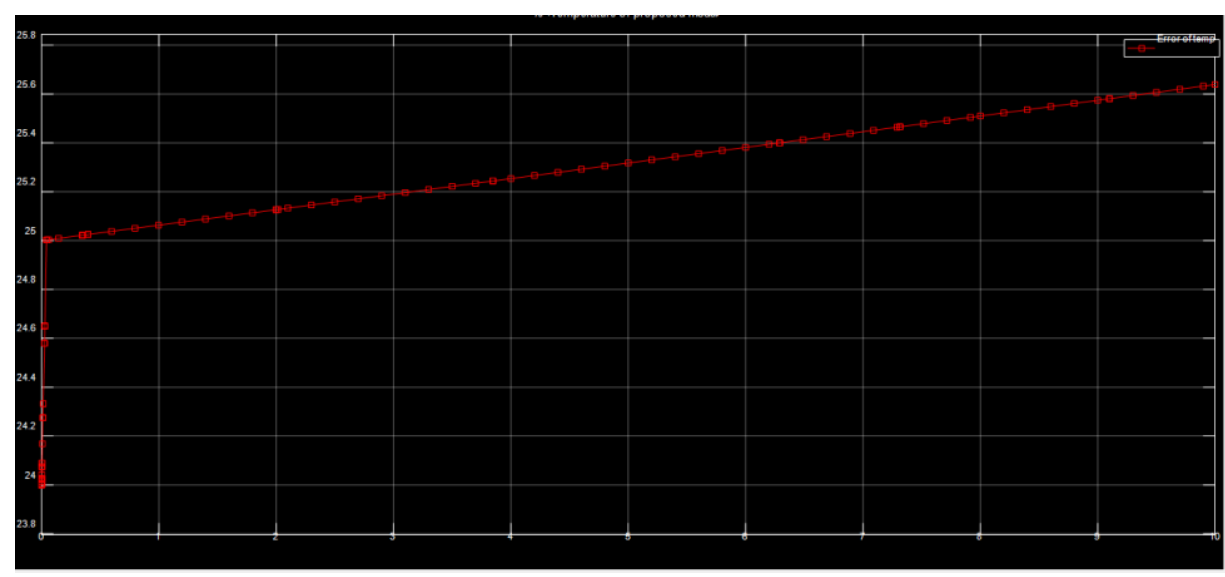

Figure 17. Sub system output of Temperature model's output.

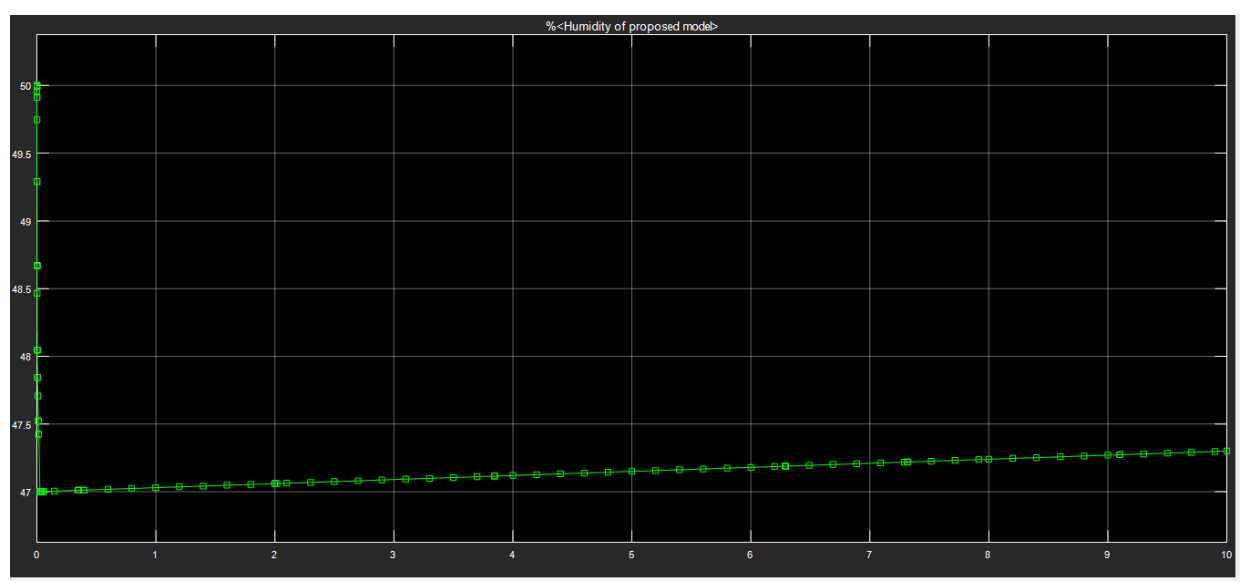

Figure 18. Sub system output of Humidity model's output.

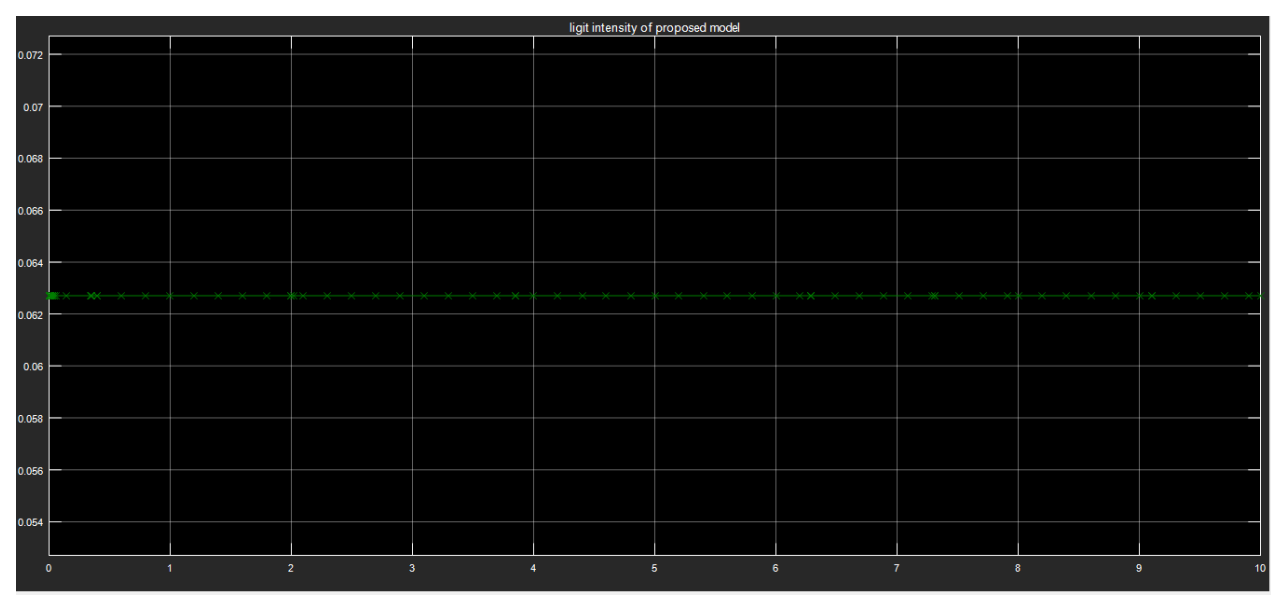

Figure 19. Sub system output of Light intensity model's output. 


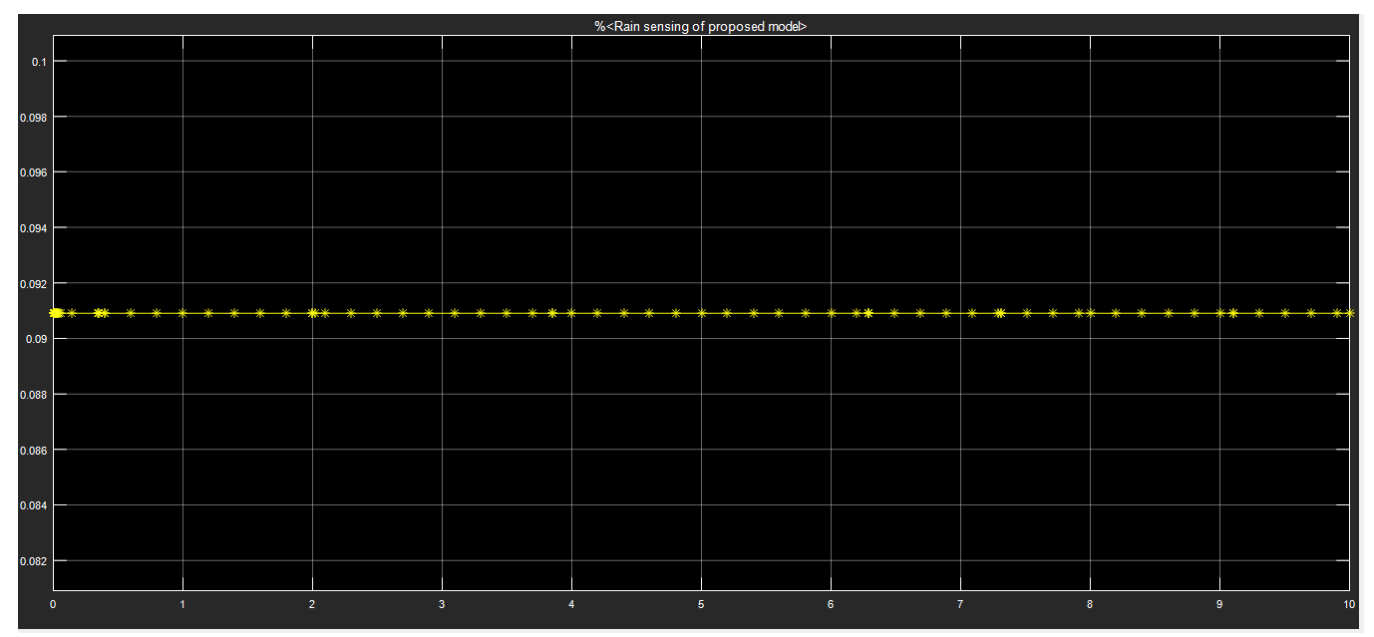

Figure 20. Sub system output of Rain sensing model's output.

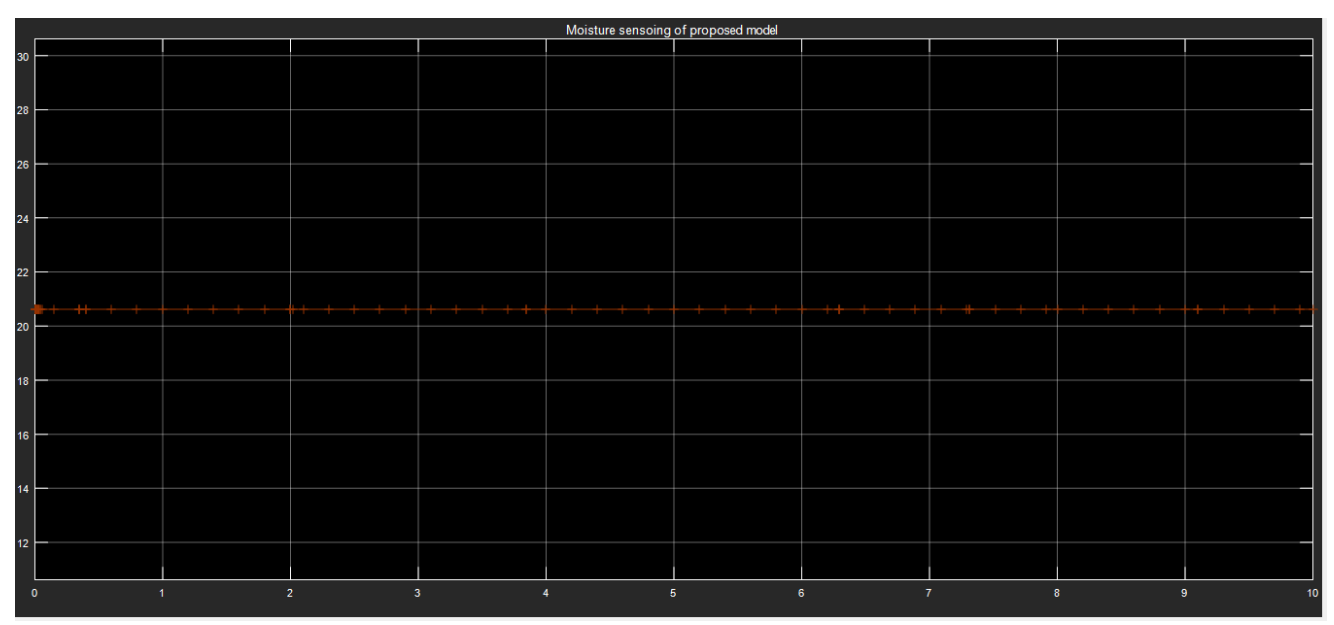

Figure 21. Sub system output of Moisture model's output.

\section{Conclusions}

This designing method makes the system efficient and better controlling. This analytical value clearly maps out the functioning of fuzzy logic in dealing with the problem of different smooth controlling in difficult situation. In this greenhouse system fuzzy logic helped to solve the complex problem without interaction physical variables. Intuitional knowledge about input and output parameters was enough to design an optimally performance of this system. This proposed system is being carried out in pro-cessing plant and in future it will help to design the advanced controlling system for various application in environment monitoring and management system. This system is mainly proposed for monitoring and maintaining the environment of greenhouse so that an eco-friendly environment for producing any kind of plant. In future more advanced controlling system can be introduced i.e. measuring $\mathrm{PH}$ for maintaining proper $\mathrm{PH}$ level of water to supply suitable water for plant. 


\section{REFERENCES}

[1] M. A. Ali.Ben.R, Aridhi.E, "Dynamic model of an agricultural greenhouse using Matlab-Simulink environment," in 16th international conference on Sciences and Techniques of Automatic control computer engineering - STA, 2015, pp. 21-23

[2] D. Das.Kumar.T, "Design of A Room Temperature and Humidity Controller Using Fuzzy Logic,"in American Journal of Engineering Research (AJER), Volume-02,Issue-11, pp. 86- 97

[3] O. A. F. Javadikia.P, Tabatabaeefar. A, "Evaluation of Intelligent Greenhouse Climate Control System, Based Fuzzy Logic in Relation to Conventional Systems," in International Conference on Artificial Intelligence and Computational Intelligence. 2009

[4] S. Gouadria.F, "Fuzzy logic controller devoted to a geothermal greenhouse," in 3rd international conference on Automation, control, Engineering and computer science, ACECS, 2016.

[5] M. Sriraman.A, "Climate Control inside a Greenhouse: An Intelligence System Approach Using Fuzzy Logic Programming,” in Journal of Environmental Informatics, 2007, pp. 14-20

[6] Z. Oliver L. Iliev, Sazdov.P, “A Fuzzy Logic Based Controller for Integrated Control of Protected Cultivation," in FactaUniversitatis, Series: Automatic Control and Robotics, 2012, pp. 119-128

[7] L. A. AlgarÃ n R.C. Iliev, Cabarcas.C.J, "Low-Cost Fuzzy Logic Control for Greenhouse Environments with Web Monitoring," in Basel, Switzerland.

[8] H. R. Hilali.A, Alami, "Control Based On the Temperature and Moisture, Using the Fuzzy Logic, "in Int. Journal of Engineering Research and Application.

[9] N. O. Caponetto. R, ortuna.L, "A Fuzzy Approach to Greenhouse Climate Control," in American Control Conference., 1998.

[10] S. Revathi.S, "Fuzzy Based Temperature Control of Greenhouse," in Science Direct, IFACPapersOnLine., 2016, pp. 549-554.

[11] F. M. Azaza.M, anougast.c, "Smart greenhouse fuzzy logic based control system enhanced with wireless data monitoring," in ISA Transaction.

[12] P. W. H. Syam.R and J., "Controlling Smart Green House Using Fuzzy Logic Method," in International Journal on Smart Material and Mechatronics., 2015.

[13] K. Heidari.M, "Climate Control of An Agricultural Greenhouse by Using Fuzzy Logic SelfTuning PID Approach," in Proceedings of the 23rd International Conference on Automation Computing., 2017

[14] M. Potdar .R.S, Patil.B.C, "Greenhouse Air-Temperature Modelling and Fuzzy Logic Control," in International Journal of Electronics Engineering Research., 2017, pp. 727-734

[15] B. J.-F. Lafont.F, “Optimized fuzzy control of a greenhouse,” in Fuzzy Sets and Systems 128, 2002, pp. $47-59$

[16] S.-L. F. Bouadila.S, Kooli.S, "Improvement of the greenhouse climate using a solar air heater with latent storage energy,” 2014, pp. 663-672

[17] F. A. A. Khalid A. Joudi, "A dynamic model and an experimental study for the internal air and soil temperatures in an innovative greenhouse," in Energy Conversion and Management 91, 2015, pp. 7682 
[18] A. M. ALI.B.Rim, ARIDHI.E, "Fuzzy Logic Controller of temperature and humidity inside an agricultural greenhouse," in 7th International Renewable Energy Congress (IREC), 2016, pp

[19] O. X. Caponetto.R, Nunnari.G, "Soft Computing for Greenhouse Climate Control," in IEEE TRANSACTIONS ON FUZZY SYSTEMS, 2000

[20] A. A. M. M. ALI.B.R, F, "Fuzzy Logic Controller of temperature and humidity inside an agricultural greenhouse," in 7th International Renewable Energy Congress (IREC), 2016

[21] B. X. S. J. Senent.S.J, Martfnez.A.M, "MIMO Predictive Control of Temperature and Humidity Inside a Greenhouse Using Simulated Annealing (SA) as Optimizerof a Multicriteria Index," inInternational Conference on Industrial, Engineering and Other Applications of Applied IntelligentSystem, 2005, pp. 271-279

[22] P. Barsoum.N, "GSM Greenhouse Monitoring and Control of Temperature and Soil Moisture," in European International Journal of Science and Technology, 2015

[23] R. Kavitha.A, "Solar Based Greenhouse Automation System for Concrete Roof,"in International Journal of Mathematical Sciences and Engineering (IJMSE), 2017

[24] M. R. K. P. Shirsath.O.D, Kamble.P, "IOT Based Smart Greenhouse Automation Using Arduino," in International Journal of Innovative Research in Computer Science Technology (IJIRCST), 2017, pp

[25] S. Hastriyandi.H, Seminar.B.K, "A Multi Sensor System For Temperature monitoring In A Greenhouse Using Remote Communication," in International Journal of Latest Research inScience and Technology, 2014

[26] http://www.circuitstoday.com/ldr-

lightdependentresistors?fbclid=IwAR2uYVvPIHUlfFMSrgN7161kaze1opdRWTcfysdDLaOmVw77JpcqNfkrTc, pp

\section{AUTHORS}

Niaz Mostakim has achieved his B.Sc. and M.Sc. degree from the dept. of Electrical and Electronic Engineering of Islamic University, Kushtia-7003, Bangladesh. He is a Lecturer of the department of Electrical and Electronic Engineering at Atish Dipankar University of Science and Technology, Uttara, Dhaka. His current interest includes internet of things (IOT), Telemedicine, Control System, Fuzzy controller, microcontroller based system design, electronics system design and development, Artificial intelligence.

Shuaib Mahmud has achieved his B.Sc. and M.Sc. degree from the dept. of Electrical and Electronic Engineering of Islamic University, Kushtia-7003, Bangladesh. He is a Lecturer of the department of Electrical and Electronic Engineering at Jatiya Kabi Kazi Nazrul Islam University, Trishal, Mymensingh, Bangladesh. His current interest includes internet of things (IOT), Control System, Fuzzy controller, microcontroller based system design, electronics system design and development, Artificial intelligence and Material science.

Khalid Hossain Jewel received his Bachelor's and Master's degree from the dept. of Electrical and Electronic Engineering of Islamic University, Kushtia-7003, Bangladesh in 2004 and 2005 respectively. In 2015 he completed his M.Phil. Degree in wireless communication. Currently he is working as an associate professor in the same department. His research interest includes Ad-hoc wireless communication. intelligent systems design, cellular mobile communication and optical fiber communication
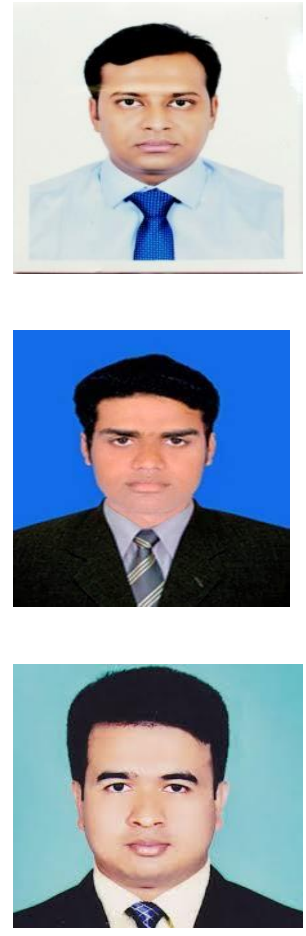